\title{
Bactérias Anaeróbias com Relevância Clínica: Classificação Taxonómica e Morfológica, Presença na Microbiota Humana e Diagnóstico Microbiológico
}

\section{Anaerobic Bacteria with Clinical Relevance: Morphologic and Taxonomic Classification, Distribution among Human Microbiota and Microbiologic Diagnosis}

\author{
João ALVES ${ }^{1}{ }^{1}$, Susana PERES ${ }^{2}$, Elsa GONÇALVES ${ }^{3}$, Kamal MANSINHO ${ }^{1,3}$ \\ Acta Med Port 2017 May;30(5):409-417 - https://doi.org/10.20344/amp.8098
}

\section{RESUMO}

A carga de bactérias anaeróbias que colonizam o organismo humano é vasta, correspondendo a cerca de $90 \%$ da biomassa humana. A relação biótica entre o ser humano e a sua microbiota configura benefícios recíprocos, embora com potencial patogénico para o Homem em situações de disbiose. Infeções com ponto de partida ou em contiguidade com a pele ou mucosas do trato intestinal, genitourinário ou respiratório alto são frequentemente polimicrobianas, devendo as bactérias anaeróbias ser invariavelmente contempladas no diagnóstico diferencial etiológico destas situações. Bacilos Gram negativo tais como Bacteroides grupo-fragilis, Fusobacterium spp., Porphyromonas spp., Prevotella spp. e cocos Gram positivo tais como Peptostreptococcus spp. destacam-se pelo seu elevado potencial de virulência e alta prevalência de isolamento em infeções supurativas e/ou abcedadas em relação contígua ou metastática com a microbiota humana. A natureza fastidiosa das bactérias anaeróbias, em especial das espécies menos aerotolerantes, condiciona particularidades nas técnicas de colheita, transporte e isolamento cultural que desafiam os clínicos e microbiologistas. Estas exigências contribuem para uma subidentificação das bactérias anaeróbias, subdiagnóstico na prática clínica e subvalorização do seu potencial etiopatogénico em focos de infeção habitualmente polimicrobianos. Conhecer a composição da flora microbiana nos diferentes locais anatómicos é objetivo primário do presente artigo. Pretende-se que os clínicos reconheçam a variabilidade e proporção dos prováveis microorganismos anaeróbios implicados em determinados processos infeciosos relacionados com a microbiota humana, com vista à optimização do processamento laboratorial de amostras e à instituição de uma antibioterapia empírica apropriada, atenta à cobertura de anaeróbios e de acordo com perfis de susceptibilidade conhecidos.

Palavras-chave: Bactérias Anaeróbias; Infecções Bacterianas; Microbiota

\section{ABSTRACT}

The wide burden of anaerobic bacteria colonizing human body comprises about $90 \%$ of its total biomass. The biotic relationship between humans and its microbiota sets reciprocal benefits, albeit with pathogenic potencial for the human being in particular dysbiosis situations. Infections adjacent to or originating from the skin or mucous membranes of the intestinal, genitourinary and upper respiratory tracts are often polymicrobial in nature, whereby should anaerobes be invariably included in the etiological differential diagnosis of these conditions. Gram negative bacilli such as Bacteroides fragilis group, Fusobacterium spp., Porphyromonas spp., Prevotella spp. and Gram positive cocci such as Peptostreptococcus spp. stand out for their high virulence and frequence of isolation in suppurative infections and abcesses with metastatic or contiguous relation to human microbiota. The fastidious nature of anaerobic bacteria, especially of less aerotolerant species, compels to particular techniques of sample collection, transport and cultural isolation that challenge clinicians and microbiologists for a full efficient practice. Such requirements bring on a poor identification of anaerobic bacteria in the clinical practice and undervaluation of its aetiopathogenic potential amongst common polymicrobial infections. An approach over microbial flora's composition in the different human anatomical sites is a primary goal of the present article. Clinicians are intended to recognize the variability and proportion of likely involved anaerobic microorganisms in certain infectious processes related to human microbiota, in order to optimize samples processing and the establishment of an appropriate empirical antibiotic therapy, mindful of anaerobic coverage and according to known susceptibility profiles.

Keywords: Bacteria, Anaerobic; Bacterial Infections; Microbiota

\section{INTRODUÇÃO}

As bactérias anaeróbias compreendem o grupo mais numeroso de microorganismos constituintes da microbiota humana, podendo, em circunstâncias particulares, atuar como patogénicos, sobretudo em locais contíguos a estruturas colonizadas. ${ }^{1}$

Vários argumentos justificam um conhecimento aprofundado sobre bactérias anaeróbias: (1) elevada frequên-

cia de infeções polimicrobianas; (2) determinadas espécies cursam com entidades clínicas graves, fulminantes e potencialmente fatais; (3) o processamento de amostras para isolamento cultural assenta em particularidades frequentemente negligenciadas (4) a antibioterapia empírica nem sempre assegura a cobertura de anaeróbios; (5) a multirresistência dos anaeróbios é uma problemática crescente.

1. Serviço de Infeciologia e Medicina Tropical. Hospital de Egas Moniz. Centro Hospitalar de Lisboa Ocidental. Lisboa. Portugal.

2. Unidade Curricular de Especialidades Médico-Cirúrgicas. Clínica de Doenças Infecciosas e Parasitárias. Faculdade de Ciências Médicas. Universidade Nova de Lisboa. Lisboa. Portugal.

3. Unidade de Infeção: Etiologia, Patogénese e Bases Terapêuticas. Faculdade de Ciências Médicas. Universidade NOVA de Lisboa. Lisboa. Portugal.

$\triangle$ Autor correspondente: João Alves. joaovazalves@hotmail.com

Recebido: 03 de agosto de 2016 - Aceite: 02 de março de 2017 | Copyright @ Ordem dos Médicos 2017 
Existe evidência epidemiológica de que as infeções por anaeróbios são subdiagnosticadas. ${ }^{2}$ Um estudo de prevalência envolvendo 15844 amostras de doentes, colhidas num período de 12 anos, contabilizou 6557 isolamentos de bactérias anaeróbias $(28,1 \%)$, ilustrando a sua elevada frequência relativa e implicação clínica. ${ }^{2}$ A clarificação de conceitos microbiológicos, clínicos e de diagnóstico poderá mitigar a negligência face a estes microorganismos.

\section{CARACTERIZAÇÃO GERAL DAS BACTÉRIAS ANAERÓBIAS}

$\mathrm{O}$ oxigénio $\left(\mathrm{O}_{2}\right)$ é um gás potencialmente nocivo, dado o seu inerente poder oxidativo. O grau de aerotolerância das bactérias dita-se pela sua capacidade de produção de enzimas que catalizam espécies reativas de $\mathrm{O}_{2}$, como a catalase, a peroxidase ou a superóxido dismutase, estabelecendo-se um espetro de aerotolerância desde o aeróbio obrigatório ao anaeróbio estrito. Microorganismos facultativos apresentam atividade metabólica adaptada à presença ou ausência de $\mathrm{O}_{2}$.
Um anaeróbio estrito não sobrevive em ar ambiente $\left([\mathrm{CO} 2]=0,04 \%,\left[\mathrm{O}_{2}\right]=21 \%\right)$ por muito tempo. Estes dividem-se em 'propriamente estritos' se só sobrevivem sob frações de $\mathrm{O}_{2}<0,5 \%$ e anaeróbios 'aerotolerantes' quando toleram ambientes com frações entre $2-8 \%$ de $\mathrm{O}_{2}$. Estes últimos incluem a maioria dos anaeróbios mais virulentos e com relevância clínica, sendo a aerotolerância fator de adaptabilidade e patogenicidade (ex. Fusobacterium nucleatum e Bacteroides fragilis).

De referir que o comportamento de fraca aerotolerância de um anaeróbio não é estanque e definitivo. Mediante modulação génica, a enzima superóxido dismutase pode ser induzida perante exposição de um anaeróbio ao $\mathrm{O}_{2}$. Alguns bacteroides, ao fim da $2^{a}-3^{a}$ geração em contacto com o ar, aumentam a transcrição dos genes que codificam a superóxido dismutase, tornando-se mais aerotolerantes, adaptados ao meio e virulentos face ao hospedeiro. ${ }^{4}$

\section{CLASSIFICAÇÃO TAXONÓMICA E MICROBIOLÓGICA}

Os anaeróbios dividem-se em Gram negativo e Gram

Tabela 1 - Algumas bactérias anaeróbias e entidades infeciosas mais frequentemente associadas

\begin{tabular}{ll}
\hline Classificação morfológica & Microorganismo \\
\hline Bacilos Gram negativo & Bacteroides grupo-fragilis
\end{tabular}

Entidade infeciosa / local de infeção

Infeções abdominais, peritonites, infeções ginecológicas, abcessos perodônticos, pneumonia de aspiração, abcessos pulmonares, infeção neonatal, bacteriemia.

Porphyromonas spp.

Prevotella melaninogenica Prevotella intermedia

Prevotella oralis

Prevotella oris

Prevotella buccae

Prevotella bivia

Prevotella disiens

Fusobacterium nucleatum

Fusobacterium necrophorum

Bacilos Gram positivo, não formadores de esporos

Actinomyces spp.

Propionibacterium acnes

Bifidobacterium spp.

Eubacterium spp.

Bacilos Gram positivo, Clostridium perfingens formadores de esporos Clostridium histolyticum Clostridium sordelli

Clostridium septicum

Clostridium difficile

Clostridium botulinum

Clostridium tetani

Cocos Gram positivo
Peptostreptococcus spp. Finegoldia magna
Infeções orofaciais.

Infeções orofaciais, pneumonia de aspiração, periondontite.

Infeções orofaciais, infeções intra-abdominais

Infeções ginecológicas/obstétricas.

Infeções orofaciais, infeções respiratórias, abcessos cerebrais, bacteriemia.

Pneumonia de aspiração, mastoidite, faringite, síndrome de Lemière, bacteriemia.

Abcessos cerebrais, mastoidite crónica, pneumonia de aspiração, infeções de cabeça e pescoço, infeções ginecológicas.

Infeções de dispositivos médicos (derivações ventriculoperitoniais, próteses cardíacas, próteses articulares).

Periodontite, otite média crónica, linfadenite cervical, infeções abdominais.

Periodontite, abcessos periodônticos, infeções de mordedura humana.

Infeções de pele e tecidos moles (gangrena gasosa, mionecrose invasiva/fasceíte necrotizante), choque tóxico.

Bacteriemia e choque tóxico em utilizadores de drogas endovenosas, pós-aborto séptico, pós-parto ou pós-trauma/procedimento ginecológico.

Enterocolite necrotizante neutropénica, bacteriemia, choque tóxico.

Diarreia associada a antibióticos, colite pseudomembranosa.

Botulismo.

Tétano.

Abcessos pulmonares, rinossinusite, abcessos cerebrais, infeções de pele e tecidos moles, infeções abdomianais, infeções de dispositivos médicos. 
positivo (Tabela 1), existindo alguns Gram variáveis, que alternam entre uma fase Gram positiva e Gram negativa, dependendo da fase de replicação - ativa versus estacionária. ${ }^{5}$ Esta particulidade pode auxiliar a identificação de Actinomyces spp., Clostridium tetani, Propionibacterium acnes, entre outros.

Os géneros Bacteroides, Prevotella, Porphyromonas e Fusobacterium destacam-se como os principais bacilos Gram negativo, sendo o género Veillonella é o principal representante de cocos Gram negativo. Os bacilos Gram positivo subdividem-se em formadores de esporos (género Clostridium) e não formadores de esporos (géneros Actinomyces, Bifidobacterium, Eubacterium, Lactobacillus e Propionibacterium). Cocos Gram positivo incluem os géneros Peptostreptococcus, Anaerococcus, Finegoldia, Parvimonas e Peptoniphilus.

\section{Bacilos Gram negativo}

Bacteroides, Prevotella, Porphyromonas e Fusobacterium são os anaeróbios mais frequentemente isolados em amostras clínicas de infeção e causadores morbimortalidade. Morfologicamente semelhantes ao exame direto, a sua distinção microbiológica assentam em propriedades testadas no laboratório: sensibilidade à penicilina, canamicina, vancomicina e colistina; crescimento seletivo em meio enriquecido com ácidos biliares; pigmentação nas colónias e emissão de fluorescência cor-de-tijolo após exposição à luz UV.

\section{Bacteroides spp. (filo Bacteroidetes)}

A classificação taxonómica definitiva deste género foi possível após a caracterização filogenética da subunidade $16 S$ do ARN ribossómico bacteriano. ${ }^{6}$ As 24 espécies identificadas classificam-se num de dois grupos: fragilis ou não-fragilis. O grupo Bacteroides fragilis inclui, entre outros, a espécie homónima Bacteroides fragilis, sendo este o anaeróbio mais relevante do ponto de vista clínico-patológico e mais frequentemente isolado em amostras clínicas. Os Bacteroides spp. são colonizantes preponderantes da mucosa intestinal, oral e genitourinária. A espécie Bacteroides fragilis corresponde apenas a $0,5 \%$ da microbiota intestinal, mas a esta se deve a maioria dos casos de bacteriemia com ponto de partida abdominal, abcessos intra-abdominais, peritonites secundárias/terciárias e infeções subcutâneas abcedadas da região perineal. Vários fatores de virulência contribuem para a sua patogenicidade: pili/fímbrias; metaloproteases; superóxido dismutase; enterotoxinas (estirpes causadoras de diarreia) e, pelo menos, oito polissacáridos capsulares (polissacárido $\mathrm{A}$ a H) cujas propriedades imunogénicas, em especial do Bacteroides fragilis, são responsáveis pela sua natureza indutora de abcesso. A endotoxina lipopolissacárida (LPS) dos Bacteroides spp.

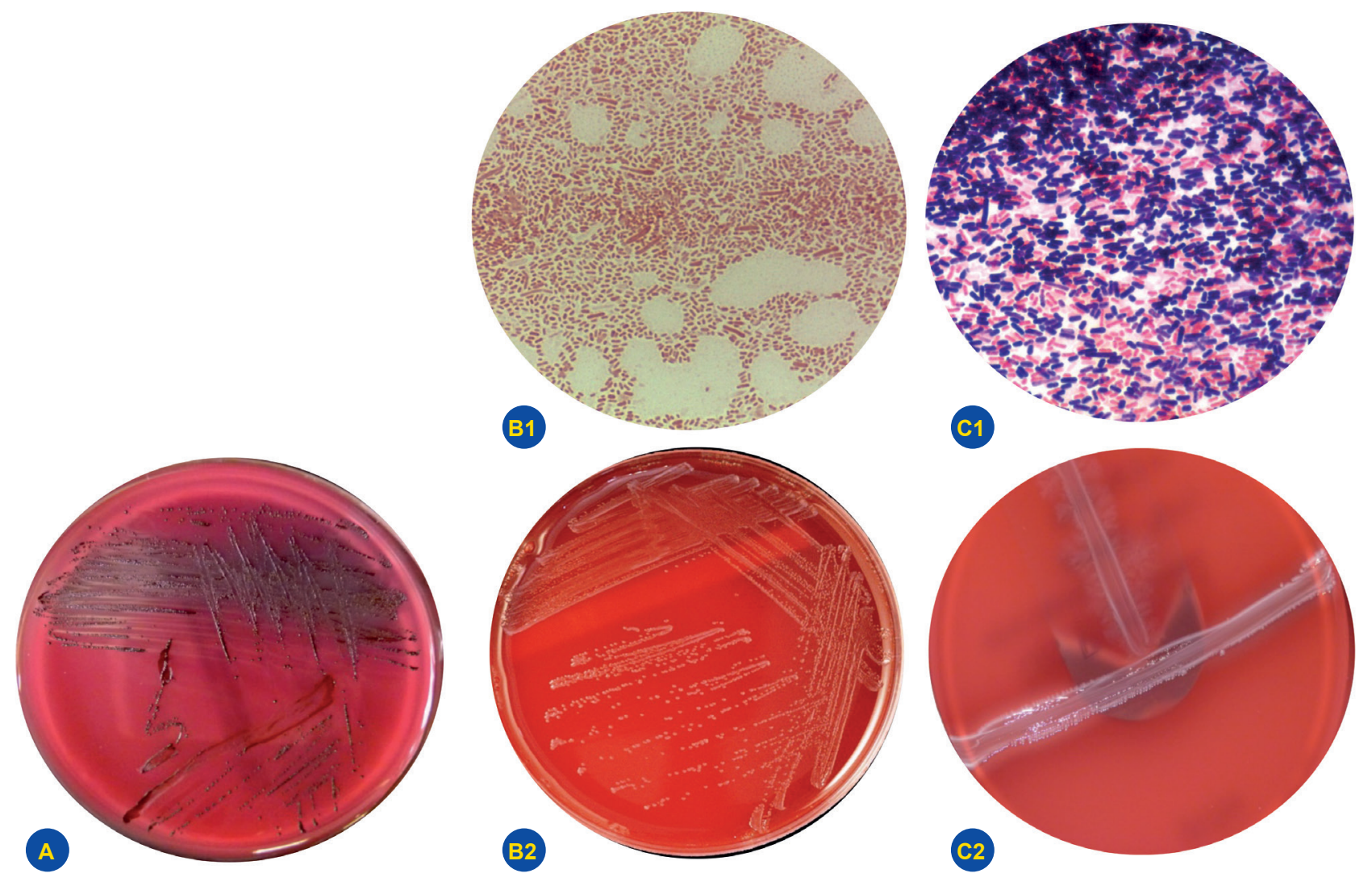

Figura 1 - Exame direto com coloração Gram e/ou isolamento cultural de: espécie pigmentada de Prevotella spp. (A); Bacteroides fragilis (B1 e B2); Clostridium perfingens (C1 e C2). A identificação de Clostridium perfingens pode ser confirmada mediante o teste de CAMP invertido, com $\beta$-hemólise potenciada na proximidade de estirpe de Streptococcus agalactiae (C2).

Imagens gentilmente cedidas pelo Laboratório de Microbiologia Clínica e Biologia Molecular do Hospital de Egas Moniz, CHLO - E.P.E. 
encerra uma imunogenicidade menor do que a do LPS de aeróbios Gram negativo. A produção constitutiva de $\beta$-lactamases por Bacteroides spp. tem implicações terapêuticas importantes na gestão de infeções intra-abdominais. A colonização oral e genital justifica a participação destes agentes na etiopatogenia de abcessos periodontais, periamigdalinos, pulmonares, pneumonia de aspiração, infeções pélvicas/obstétricas e neonatais.

\section{Prevotella e Porphyromonas spp. (filo Bacteroidetes)}

A pigmentação das colónias de Prevotella spp. e Porphyromonas spp. (Fig. 1) bem como a sua fluorescência cor-de-tijolo após exposição à luz ultravioleta (UV) auxiliam a identificação das estirpes mais patogénicas: Prevotella intermedia, Prevotella melaninogenica, Prophyromonas asaccharolytica e Prophyromonas gengivalis, entre outras. São agentes pleomórficos, bacilares ou cocobacilares e colonizam predominantemente a mucosa oral e vaginal, sendo importantes agentes de infeções ginecológicas/obstétricas (Prevotella bivia e Prevotella disiens), periodontite aguda, abcessos dentários e outras entidades com ponto de partida na cavidade oral (pneumonia de aspiração, abcessos pulmonares, otite média, rinossinusite, mastoidite, abcessos cerebrais, paroníquias e abcessos cervicais profundos.

\section{Fusobacterium spp. (filo Fusobacter)}

São agentes pleomórficos, apresentando formas cocobacilares ou bacilares filamentosas com extremidades afiladas (a morfologia fusiforme é característica das estirpes mais patogénicas). Neste género incluem-se algumas das espécies anaeróbias mais virulentas, como o Fusobacterium necrophorum, Fusobacterium nucleatum e Fusobacterium mortiferum. São agentes capsulados com propriedades abcessogénicas. Contrariamente aos géneros Bacteroides, Prevotella e Porphyromonas, o LPS constituinte da membrana plasmática dos Fusobacterium spp. detém de elevado potencial endotóxico, comparável ao de aeróbios Gram negativo, podendo desencadear quadros de choque séptico.

Colonizam a orofaringe e biofilmes dentários, contribuindo para infeções com origem ou contíguas à cavidade oral: periodontite aguda/crónica, abcessos dentários, otite média, rinossinusite, faringoamigdalites, abcessos retro/ parafaríngeas, síndrome de Lemièrre e infeções intracranianas. Num estudo norte-americano que incluiu 312 adultos jovens com faringite aguda, o Fusobacterium necrophorum foi o microorganismo mais frequentemente isolado, com incidência superior ao Streptococcus $\beta$-hemolítico dos grupos A, C ou G nesta faixa etária. ${ }^{7}$

\section{Cocos Gram negativo \\ Veillonella spp. (filo Firmicutes)}

Dos três géneros de cocos anaeróbios Gram negativo descritos (Veillonella, Acidaminococcus e Megasphaera), apenas o primeiro tem relevância epidemiológica. O seu significado clínico é incerto, sendo considerados organis- mos de baixa virulência. ${ }^{8}$ Destacam-se as espécies VeiIlonella parvula, Veillonella atypica e Veillonella dispar, que colonizam predominantemente a cavidade oral, mas também a mucosa intestinal e genitourinária. São agentes pioneiros na colonização dos sulcos gengivais, servindo de substrato, em coagregação com Streptococcus spp., para o desenvolvimento de biofilmes dentários. Contabilizam 10\% das primeiras comunidades bacterianas a fixarem-se sobre o esmalte dentário. ${ }^{9}$

\section{Bacilos Gram positivo - formadores de esporos Clostridium spp. (filo Firmicutes)}

São agentes pleomórficos, com morfologia variando entre formas cocóides (Fig. 1) ou filamentosas longas e encurvadas. Em condições adversas, os Clostridia entram em fase de esporulação, desenvolvendo um esporo terminal que pode auxiliar a sua identificação. São importantes constituintes da microbiota intestinal de vertebrados $\left(10^{8}\right.$ - $10^{9}$ organismos/grama de fezes em $70 \%$ dos indivíduos humanos), tendo distribuição ubiquitária (esporos e formas vegetativas) nos solos e objetos contaminados com excrementos animais.

Existem mais de 200 espécies descritas, sendo as mais frequentemente isoladas: Clostridium perfingens, Clostridium septicum, Clostridium histolyticum e Clostridium sordellii. São o género bacteriano com produção mais variada de histotoxinas proteicas (neurotoxinas, enterotoxinas, necrotoxinas, colagenases, DNAses, neuraminidases, lipases e lecitinases), justificando a sua extrema virulência e implicação em quadros infeciosos agressivos, sistémicos e potencialmente fatais. A a-toxina, uma lecitinase, é a mais histotóxica das toxinas extracelulares secretadas pelo género Clostridium, particularmente pelo Clostridium perfingens.

O trato intestinal ou a via transcutânea traumática são portas de entrada possíveis, originando entidades clínicas com elevada mortalidade associada: mionecrose invasiva, fasceíte necrotizante/gangrena gasosa, enterocolite necrotizante e choque tóxico. A colonização da mucosa vaginal ocorre por contaminação a partir da região perianal, havendo casos descritos de endometrite necrotizante e doença inflamatória pélvica por Clostridium spp., na sequência de abortos sépticos e procedimentos cirúrgicos ginecólogicos. A utilização de drogas endovenosas é fator de risco para infeção por Clostridium spp. Em 1999-2000, um surto de nove casos de fasceíte necrotizante por $C$. sordellii afetou consumidores de heroína endovenosa na Califórnia, alguns complicados de choque tóxico e morte. ${ }^{10}$

Outras espécies, como o Clostridium botulinum, Clostridium tetani e Clostridium difficile originam entidades clínicas bem descritas, com fisiopatologia também assente na produção de exotoxinas: botulismo, tétano e colite pseudomembranosa, respetivamente.

\section{Bacilos Gram positivo: não formadores de esporos}

A sua patogenicidade varia consoante os géneros: alguns estabelecem uma relação biótica com o hospedeiro invariavelmente inócua, podendo outros causar 
situações excepcionais de infeção disseminada ou focalizada grave, especialmente em imunodeprimidos. Incluem-se neste grupo os géneros Actinomyces, Bifidobacterium, Eubacterium, Lactobacillus e Propionibacterium, embora não se relacionem necessariamente do ponto de vista filogenético, distribuindo-se pelos filos Firmicutes e Actinobacteria. ${ }^{11}$

\section{Lactobacillus, Bifidobacterium e Eubacterium spp. (filo Firmicutes)}

Incluem dezenas de espécies, geralmente pouco virulentas para indivíduos imunocompetentes. Raramente isolados em amostras clínicas e, mais raro ainda, como agentes etiopatogénicos únicos.

Os Lactobacilli (L.) colonizam abundantemente o trato vaginal, intestinal e cavidade oral, ocupando um nicho ecológico extenso que impede a proliferação de agentes mais patogénicos. Na mucosa vaginal e retal, Lactobacilli produtores de ácido láctico e peróxido de hidrogénio frenam a proliferação de agentes responsáveis pela vaginose bacteriana. ${ }^{12}$ Neste sentido, os Lactobacilli têm sido estudados como probióticos na profilaxia de diarreia por Clostridium difficile e vaginose bacteriana. ${ }^{13} \mathrm{Em}$ imunocomprometidos submetidos a procedimentos dentários ou colonoscopia, uma bacteriemia subsequente por Lactobacilli (por ex. $L$. rhamnosus) pode ter significado clínico, havendo relatos de endocardite subaguda, de tratamento moroso e elevada letalidade associada. ${ }^{14}$

Os Bifidobacteria são considerados pouco patogénicos, embora podendo participar na fisiopatologia da periodontite crónica. São pioneiros na colonização do intestino do recém-nascido durante o aleitamento materno, interferindo na diferenciação do tecido linfóide associado à mucosa gastrointestinal e na indução de imunotolerância a este nível. ${ }^{15}$

Os Eubacteria colonizam a cavidade oral, biofilmes dentários e sulcos gengivais, com relevância na fisiopatologia da doença periodontal e abcessos peridentários. Têm ainda importância etiopatogénica em infeções pós-mordedura humana.

\section{Actinomyces spp. (filo Actinobacteria)}

A actinomicose é uma entidade pouco comum, conhecida na literatura médica como 'grande imitadora'. ${ }^{16}$ Características como a evolução crónica, formação de massas de crescimento lento (abcessos frios) e refratariedade a ciclos curtos de antibioterapia, mimetizam neoplasias, tuberculose ou nocardiose. Curiosamente existe proximidade filogenética entre os géneros Actinomyces, Mycobacterium e Nocardia, pertencendo todos ao filo Actinobacteria. Ao exame direto, os Actinomyces spp. são bacilos filamentosos longos e ramificados, assemelhando-se a micélios fúngicos. Todas estas particularidades confundem os clínicos, atrasando frequentemente o diagnóstico de actinomicose.

Existem mais de 30 espécies descritas. Actinomyces israelii, Actinomyces gerencseriae e Actinomyces meyeri são alguns dos com maior relevância clínica. Colonizam sulcos gengivais, criptas amigdalinas, cólon e vagina, sendo responsáveis por infeções indolentes, supurativas e que envolvem qualquer tecido/órgão. Os focos de actinomicose apresentam tipicamente grânulos de enxofre amarelados e visíveis a olho nú, ajudando na suspeição clínica da actinomicose. Como apresentações clínicas clássicas destacam-se a actinomicose cervicofacial geralmente consequente a infeção periodontal; actinomicose pélvica em mulheres com dispositivos intrauterinos e actinomicose pulmonar em fumadores com periodontite crónica. ${ }^{17}$ Antibioterapia prolongada até 12 meses é necessária, podendo a cirurgia abreviar o seu curso. ${ }^{17}$

\section{Propionibacterium spp. (filo Actinobacteria)}

Geralmente pouco virulento, o Propionibacterium acnes é a principal espécie com significado clínico. É o anaeróbio colonizador da pele mais prevalente, especialmente em regiões anatómicas ricas em folículos pilosebáceos (face, canal auditivo externo, axilas, tronco) onde o inóculo bacteriano aeróbio é menor. ${ }^{18} \hat{E}$ ainda comensal da flora oral, conjuntival e intestinal. ${ }^{19}$ Para além da implicação na patogénese do acne vulgaris, o Propionibacterium acnes tem-se associado a infeções de dispositivos médicos, nomeadamente próteses articulares, derivações ventriculoperitoneais, implantes mamários, lentes intraoculares e próteses valvulares cardíacas no pós-operatório tardio. ${ }^{20} \mathrm{~A}$ endocardite de válvula nativa também está descrita. ${ }^{21}$ Especula-se ainda a implicação do Propionibacterium acnes como agente precipitante de sarcoidose ou da síndrome SAPHO (sinovite, acne, pustulose palmoplantar, hiperostose e osteíte). ${ }^{22}$

\section{Cocos Gram positivo \\ Peptostreptococcus, Anaerococcus, Finegoldia, Parvimonas e Peptoniphilus spp. (filo Firmicutes)}

São os anaeróbios Gram positivo mais prevalentes em amostras clínicas correspondendo a $25-30 \%$ dos isolamentos de anaeróbios. ${ }^{23}$ São organismos virulentos e o seu valor patogénico em infeções polimicrobianas é negligenciado. A organização taxonómica deste grupo heterogénio tem sofrido sucessivas reclassificações. Estirpes que no passado se classificavam como Peptostreptococcus, são hoje incluidas em novos géneros: Anaerococcus, Finegoldia, Parvimonas e Peptoniphilus.

Finegoldia magna, Parvimonas micra, Peptoniphilus harei e Peptostreptococcus anaerobius são algumas das espécies com maior potencial patogénico. ${ }^{24}$ Idade avançada, imunodepressão e presença de material protésico contituem risco para o estabelecimento de infeções por cocos anaeróbios Gram positivo. ${ }^{23}$

São constituintes prevalentes da microbiota da pele, orofaringe, trato respiratório, intestinal e genitourinário, associando-se a patologia infeciosa contígua a estes locais anatómicos. Num estudo de 2004 , os cocos Gram positivo foram os agentes anaeróbios mais frequentemente isolados em 198 empiemas pleurais..$^{25}$ O Peptostreptococcus anaerobius tem implicação etiopatogénica importante na vaginose bacteriana. A Finegoldia magna, à semeIhança dos seus congéneres aeróbios (Streptococcus e 
Staphylococcus spp.), sintetiza fatores de adesão implicados na colonização de superfícies protésicas, pelo que uma bacteriemia por este agente pode levantar a suspeita de infeção associada a dispositivo. ${ }^{26}$.

\section{MICROBIOTA HUMANA: QUE ANAERÓBIOS NOS COLONIZAM EM CADA LOCAL ANATÓMICO?}

O organismo humano é um ecossistema complexo, correspondendo $a \approx 90 \%$ da biomassa humana a uma flora microbiana variada composta de mais de 300 espécies de bactérias ${ }^{27}$ em várias estruturas anatómicas: pele, cavidade oral, faringe, laringe, mucosa conjuntival, canal auditivo externo, mucosa nasal, seios perinasais, trato digestivo distal, vagina e uretra masculina e feminina. Desta coevolução ao longo de milhões de anos, resultou uma relação biótica de comensalismo ou mesmo mutualismo, com benefícios bem documentados tanto para os microorganismos colonizantes como para o hospedeiro humano.

Mais de $99 \%$ da microbiota cultivável são anaeróbios estritos. No cólon, a sua frequência relativa alcança os $99,9 \% .^{18}$ Anaeróbios e aeróbios colonizantes convivem num sinergismo assente no intercâmbio de metabolitos essenciais e na redução do potencial oxidativo do meio pelos aeróbios e anaeróbios facultativos que consomem $\mathrm{O}_{2}$, favorecendo a proliferação dos anaeróbios estritos.

Sumariamente, destacam-se como propriedades mutualísticas da microbiota anaeróbia humana: (1) ocupação de um nicho ecológico de outra forma apropriado por agentes patogénicos - fenómeno de "interferência bacteriana"; (2) produção de metabolitos absorvidos e utilizados pelo hospedeiro (ex. síntese de vitamina $\mathrm{K}_{2}$, fermentação de hidratos de carbono, metabolismo de ácidos biliares); (3) indução de imunotolerância que previne estados inflamatórios crónicos futuros e (4) modulação de genes do hospedeiro, direcionando a maturação vascular, do sistema nervoso mioentérico e do tecido linfóide associado à mucosa gastrointestinal. ${ }^{28}$

Conhecer a composição geral da flora microbiana humana nos diferentes locais permite conjeturar que microorganismos poderão estar implicados em processos infeciosos adjacentes.

\section{Pele}

Staphylococcus, Streptococcus, Corynebacterium e Pityrosporum spp. são colonizantes transitórios e potencialmente patogénicos da pele. O seu crescimento é inibido por residentes anaeróbios permanentes, nomeadamente Propionibacterium spp., produtores de ácidos gordos livres bactericidas e fungicidas, resultando na sua preponderância sobre aeróbios e fungos comensais. A pele da região perioral e dedos, região perineal e genitais externos aproxima-se da composição da flora da cavidade oral, intestinal e vaginal, respetivamente. ${ }^{27}$

O Propionibacterium acnes é o colonizante anaeróbio predominante (100 a 1000 vezes mais prevalente que outros anaeróbios). Propionibacterium granulosum, Propionibacterium avidum e Peptostreptococcus spp. são exemplos de colonizantes anaeróbios menos numerosos. A proporção de Propionibacterium acnes aumenta consideravelmente após a puberdade, paralelamente ao aumento de folículos pilosebáceos na face, regiões auriculares e tronco. Estas são superfícies densamente colonizadas, embora com menor variabilidade de espécies.

\section{Cavidade oral}

A flora oral varia, quantitativa e qualitativamente, consoante o local anatómico, a higiene oral e a ocorrência de periodontite crónica. O rácio anaeróbios/aeróbios alcança um máximo a nível dos sulcos gengivais e criptas amigdalinas (1000:1), onde coexistem bactérias de praticamente todos os géneros anaeróbios. Amostras gengivais contabilizam até $10^{12}$ bactérias anaeróbias $/ \mathrm{ml}$, superior à sua concentração na saliva $\left(10^{9}\right.$ bactérias anaeróbias $\left./ \mathrm{ml}\right){ }^{4}$

Bacteroides não-fragilis, Prevotella, Porphyromonas spp. são os géneros mais abundantes. Fusobacterium, Actinomyces, Lactobacillus, Bifidobacterium, Eubacterium, Propionibacterium, Veillonella spp. e cocos Gram positivo são também frequentes.

\section{Trato gastrointestinal}

A colonização do sistema digestivo inicia-se no parto aquando da passagem pelo canal vaginal ou no período pós-natal em indivíduos nascidos por cesariana. A carga bacteriana aumenta do estômago até ao cólon, num total de 10 a 100 triliões de organismos $(99,9 \%$ da microbiota humana), residentes maioritariamente no ílio terminal e cóIon.

No cólon contabilizam-se $\approx 10^{12}$ bactérias $/ \mathrm{ml}$ de fezes, com rácio anaeróbios/aeróbios de 1000:1.4 Predominam estirpes de Bacteroides grupo-fragilis ( $B$. fragilis, $B$. thetaiotaomicron, B. vulgatus, Parabacteroides distasonis, etc). Bifidobacterium, Lactobacillus e Clostridium spp. são também prevalentes. Em menor número, encontram-se estirpes de Fusobacterium, Actinomyces, Propionibacterium e cocos anaeróbios Gram positivo.

No estômago, a microbiota é diminuta, podendo-se equivaler qualitativamente à flora oral, no caso de toma de antiácidos ou entubação nasogástrica. ${ }^{29,30}$

\section{Trato genitourinário feminino}

Uma amostra vaginal contém $\approx 10^{8}$ bactérias $/ \mathrm{ml},{ }^{4} \mathrm{com}$ rácio anaeróbios/aeróbios menor do que noutros locais (10:1). Os Lactobacilli são os principais colonizantes, com predominância alcançada após a puberdade, dado o aumento da produção de glicogénio pela mucosa vaginal. $\mathrm{Na}$ mulher adulta, incluindo gravidez, os Lactobacilli proliferam e acidificam o canal vaginal por fermentação láctica do glicogénio (Lactobacillus acidophilus), antagonizando o crescimento de agentes patogénicos: Streptococcus agalactiae, Staphylococcus spp., Candida spp., Gardnerella vaginalis, Enterococcus spp. e Enterobacteriaceae. ${ }^{31}$

A microbiota genitourinária anaeróbia inclui ainda Clostridium ramosum, Clostridium bifermentans, Peptostreptococcus anaerobius, Prevotella disiens, Prevotella 
Tabela 2 - Colheita de amostras para cultura de anaeróbios

\begin{tabular}{l} 
Procedimentos aceitáveis \\
\hline Aspiração com agulha de fluídos biológicos estéreis.* \\
Aspiração de urina por punção suprapúbica. \\
Aspiração traqueal percutânea. \\
Punção pulmonar transtorácica. \\
Lavado broncoalveolar com cateter protegido (duplo lúmen).† \\
Culdocentese após descontaminação vaginal.ł \\
Aspiração percutânea ou transmucosa de abcesso fechado. \\
Aspiração de exsudado profundo de úlcera cutânea. \\
\hline Procedimentos não aceitáveis
\end{tabular}

Zaragatoa nasal, orofaríngea ou gengival.

Colheita de expetoração.

Aspiração oro ou nasotraqueal de secreções.

Broncofibroscopia com cateter não protegido.

Aspiração de conteúdo por ileostomia ou colostomia.

Colheita de fezes.§

Zaragatoa retal.

Zaragatoa vaginal ou cervical.

Urina de jato médio ou de catéter vesical.

Zaragatoa ou aspiração de exsudado superficial de úlcera cutânea.

* Sangue, líquido pleural, peritonial, sinovial, cefalorraquidiano; † A cultura deve ser realizada segundo método quantitativo; $\ddagger$ Aspiração com agulha do espaço retouterino, por via transvaginal; § Excepto para pesquisa de toxina de Clostridium difficile.

bivia, Porphyromonas, Bacteroides grupo-fragilis, Fusobacterium, Veillonella, Bifidobacterium e Eubacterium spp. ${ }^{(27)}$

\section{DIAGNÓSTICO MICROBIOLÓGICO}

A menor notoriedade clínica dos anaeróbios prende-se com a sua natureza fastidiosa. O seu crescimento cultural é lento e tecnicamente laborioso. Métodos de colheita, trans- porte e processamento são raramente realizados de forma apropriada. ${ }^{27} \mathrm{Em}$ infeções mistas, a identificação cultural menos exigente de aeróbios/anaeróbios facultativos resulta frequentemente num diagnóstico etiológico incompleto, com subnotificação de infeções por anaeróbios estritos.

\section{Colheita}

A validação microbiológica da etiologia bacteriana anaeróbia pressupõe minimizar a contaminação da amostra pela flora adjacente aquando da colheita. Com efeito, existem procedimentos de colheita 'aceitáveis' e 'não aceitáveis' para o isolamento de anaeróbios (Tabela 2). A coIheita assética de um fluido estéril (sangue, líquido pleural, peritonial, sinovial, cefalorraquidiano) é apropriada para a cultura de anaeróbios. A aspiração percutânea de abcesso com agulha exige a descontaminação da superfície com clorohexidina ou iodopovidona e a obtenção de pelo menos $2 \mathrm{ml}$ de exsudado, que deve ser imediatamente inoculado num meio de transporte em anaerobiose (Fig. 2). Em alternativa, deve-se eliminar o excesso de ar da seringa, vedar e transportar rapidamente ao laboratório, sob o risco de difusão do $\mathrm{O}_{2}$ através de seringas de plástico em $\approx 30 \mathrm{mi}-$ nutos. O exame microbiológico de biópsia de tecido apresenta também boa rentabilidade no isolamento de anaeróbios. Colheitas por zaragatoa não são recomendadas, pela elevada probabilidade de contaminação, exposição ao ar e quantidade diminuta de produto.

\section{Transporte}

Após a colheita, o contato com $\mathrm{O}_{2}$ inviabiliza os anaeróbios estritos em $<1$ hora. Um transporte em atmosfera controlada é pois um passo crítico para o isolamento cultural destes agentes, existindo sistemas de transporte, comercialmente disponíveis, adequados ao acondicionamento em anaerobiose de fluidos biológicos e peças de
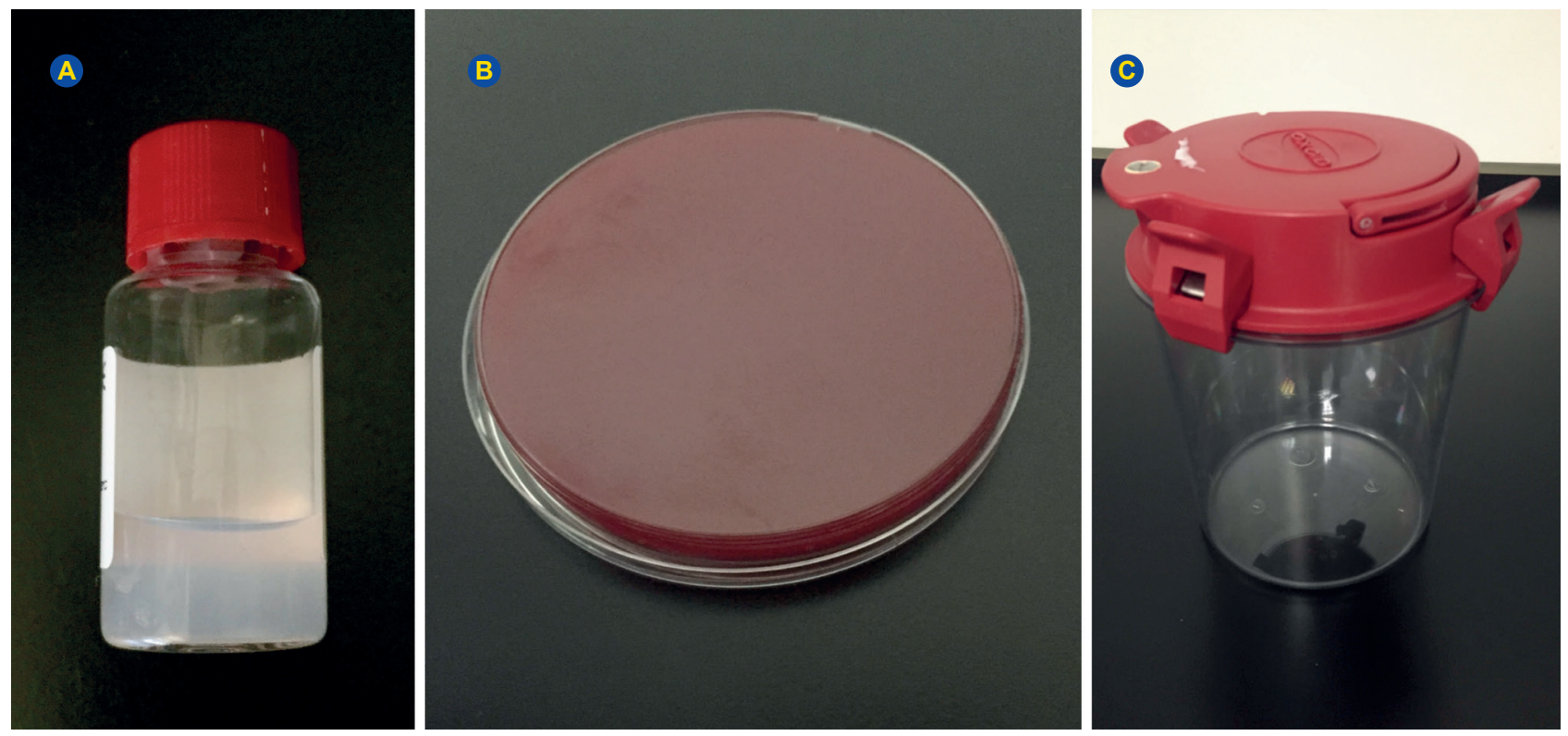

Figura 2 - Material de colheita, transporte e processamento de amostras biológicas em anaerobiose: (A) meio de colheita e transporte específico para anaeróbios; (B) meio de cultura em gelose de sangue específico para o crescimento de anaeróbios fastidiosos; (C) jarra de anaerobiose para acondicionamento das amostras cultivadas em atmosfera anaeróbia controlada. Imagens gentilmente cedidas pelo Laboratório de Microbiologia Clínica e Biologia Molecular do Hospital de Egas Moniz, CHLO - E.P.E. 
biopsia. ${ }^{32,33}$ Estes possuem, por norma, um meio semi-sólido esterilizado, pré-reduzido, em atmosfera anóxica, contendo um indicador de oxirredução, preservando a maioria dos anaeróbios viáveis até 48 horas. ${ }^{33}$ Não obstante, recomenda-se o transporte célere da amostra para o laboratório de microbiologia, com vista a evitar o sobrecrescimento de anaeróbios facultativos, em detrimento de estirpes mais fastidiosas. ${ }^{26,32-34} \mathrm{O}$ transporte deve ser realizado à temperatura ambiente, nunca refrigerado nem excedendo os $37^{\circ} \mathrm{C} .^{32}$

\section{Processamento}

Para além do exame macroscópico, o exame direto fornece dados de diversidade e proporção dos microorganismos, permitindo selecionar meios de cultura e controlar a validade do isolamento obtido.

Detalhes sobre as complexos metodologias de cultura ultrapassam o objectivo desta revisão, podendo ser consultadas em manuais de Microbiologia. ${ }^{34,35}$ Como requisito mínimo para o isolamento de anaeróbios, a amostra deve ser prontamente inoculada em meio de gelose de sangue não seletivo, pré-reduzido e enriquecido com fitomenadiona e hemina, ${ }^{27}$ existindo igualmente meios seletivos para o crescimento de estirpes mais fastidiosas. O acondicionamento hermético em jarras de anaerobiose garante a manutenção de atmosfera anóxica (Fig. 2), por um tempo de incubação que deve ser de 5 - 7 dias (até 14 dias se suspeita de actinomicose). Neste intervalo, testes bioquímicos/manuais podem ser aplicados para identificação de género e espécie. Técnicas de biologia molecular (amplificação do gene 16S ARNr) têm tido uso crescente no diagnóstico microbiológico, sensível e específico. ${ }^{36}$

Testes de susceptibilidade aos antimicrobianos são re- comendados em circunstâncias precisas: (1) infeção grave potencialmente fatal; (2) refratariedade/recidiva após antibioterapia empírica; (3) dados incertos sobre o perfil de susceptibilidade do agente isolado; (4) reconhecido perfil de resistência - incidência crescente de Bacteroides grupo-fragilis produtores de $\beta$-lactamases; (5) agente particularmente virulento; (6) necessidade de antibioterapia prolongada, em contextos como osteomielite, abcesso não drenado ou infeção protésica. ${ }^{37}$

\section{CONSIDERAÇÕES FINAIS}

Infeções com ponto de partida na pele ou mucosa intestinal, genitourinária ou respiratória são frequentemente polimicrobianas, devendo as bactérias anaeróbias ser invariavelmente contempladas no diagnóstico diferencial etiológico destas situações.

Conhecer a composição da flora microbiana, permite reconhecer a variabilidade e proporção dos possíveis microorganismos anaeróbios implicados em determinados processos infeciosos em relação contígua ou metastática com a microbiota humana, com vista à optimização do exigente processamento laboratorial de amostras e à instituição de uma antibioterapia empírica apropriada, atenta à cobertura de anaeróbios.

\section{CONFLITOS DE INTERESSE}

Os autores declaram não terem qualquer conflito de interesse relativamente ao presente artigo.

\section{FONTES DE FINANCIAMENTO}

Os autores declaram não ter recebido subsídios ou bolsas para a elaboração do artigo.

\section{REFERÊNCIAS}

1. Jenkins SG. Infections due to anaerobic bacteria and the role of antimicrobial susceptibility testing of anaerobes. Rev Med Microbiol. 2001;12:1-12.

2. Brook I. Recovery of anaerobic bacteria from clinical specimens in 12 years at two military hospitals. J Clin Microbiol. 1988;26:1181-8.

3. Jousimies-Somer HR, Summanen P, Citron DM, Baron EJ, Wexler HM, Finegold SM. Anaerobic bacteriology manual. $6^{\text {th }}$ ed. Belmont: Star Publishing; 2002.

4. Bennett JE, Dolin R, Blaser MJ. Mandell, Douglas, and Bennett's Principles and Practice of Infectious Diseases. $7^{\text {th }}$ ed. Philadelphia: Elsevier; 2010.

5. Beveridge TJ. Mechanism of gram variability in select bacteria. $J$ Bacteriol. 1990;172:1609-20.

6. Paster BJ, Dewhirst FE, Olsen I, Frayser GJ. Phylogeny of bacteroides, prevotella, and porphyromonas spp. and related bacteria. J Bacteriol. 1994;176:725-32.

7. Centor RM, Prescott-Atkinson T, Ratliff AE, Xiao L, Crabb DM, Estrada $\mathrm{CA}$, et al. The clinical presentation of Fusobacterium-positive and streptococcal-positive pharyngitis in a university health clinic: a crosssectional study. Ann Intern Med. 2015;162:241-7.

8. Vesthi T, Ozen A, Andersen SC, Kaas RS, Lukjansenko O, Bohlin J, et al. Veillonella, firmicutes: microbes disguised as gram-negatives. Stand in Genomic Sci. 2013;9:431-48.

9. Diaz PI, Chalmers NI, Rickard AH, Kong C, Milburn C, Palmer RJ, et al. Molecular characterization of subject-specific oral microflora during initial colonization of enamel. Appl Environ Microbiol. 2006;72:2837-48.

10. Kimura AC, Higa JI, Levin RM, Simpson G, Vargas Y, Vugia DJ. Outbreak of necrotizing fasciitis due to clostridium sordellii among black-tar heroin users. Clin Infect Dis. 2004;38:e87-91.
11. Hall V, Cospsey S. Propionibacterium, lactobacillus, actinomyces, and other non-spore-forming anaerobic gram-positive rods . In: Jorgensen J, Pfaller M, Carroll K, Funke G, Landry M, Richter S, et al, editors. Manual of Clinical Microbiology. $11^{\text {th }}$ ed. Washington: ASM Press; 2015. p. 92039.

12. Antonio MA, Rabe LK, Hillier SL. Colonization of the rectum by lactobacillus species and decreased risk of bacterial vaginosis. $\mathrm{J}$ Infect Dis. 2005;192:394-8.

13. Reid G, Jass J, Sebulsky MT, McCormick JK. Potential uses of probiotics in clinical practice. Clin Microbiol Rev. 2003;16:658-72.

14. Griffiths GK, Daly JS, Dodge RA. Two cases of endocarditis due to Lactobacillus species: antimicrobial susceptibility, review, and discussion of therapy. Clin Infect Dis. 1992;15:250-5.

15. Konieczna P, Akdis CA, Quigley EM, Shanahan F, O'Mahony L. Portrait of an immunoregulatory bifidobacterium. Gut Microbes. 2012;3:261-6.

16. Acevedo F, Baudrand R, Letelier LM, Gaete P. Actinomycosis: a great pretender. Case reports of unusual presentations and a review of the literature. Int J Infect Dis. 2008;12:358-62.

17. Valour F, Sénéchal A, Dupieux C, Karsenty J, Lustig S, Breton P. Actinomycosis: etiology, clinical features, diagnosis, treatment, and management. Infect Drug Resist. 2014;7:183-97.

18. Grice EA, Segre JA. The human microbiome: our second genome. Annu Rev Genomics Hum Genet. 2002;13:151-70.

19. Perry AL, Lambert PA. Propionibacterium acnes. Lett Appl Microbiol. 2006;42:185-8.

20. Portillo ME, Corvec S, Borens O, Trampuz A. Propionibacterium acnes: an underestimated pathogen in implant-associated infections. Biomed Res Int. 2013;2013:804391.

21. Mohsen AH, Price A, Ridgway E, West JN, Green S, McKendrick MW 
Propionibacterium acnes endocarditis in a native valve complicated by intraventricular abscess: a case report and review. Scand J Infect Dis. $2001 ; 33: 379-80$.

22. Colina M, Lo Monaco A, Khodeir M, Trotta F. Propionibacterium acnes and SAPHO syndrome: a case report and literature review. Clin Exp Rheumatol. 2007;25:457-60.

23. Murphy EC, Frick I. Gram-positive anaerobic cocci: commensals and opportunistic pathogens. FEMS Microbiol Rev. 2013;37:520-53.

24. Wildeboer-Veloo AC, Harmsen HJ, Welling GW, Degener JE. Development of $16 \mathrm{~S}$ rRNA-based probes for the identification of Grampositive anaerobic cocci isolated from human clinical specimens. Clin Microbiol Infect. 2007;13:985-92.

25. Boyanova L, Djambazov V, Gergova G, lotov D, Petrov D, Osmanliev $\mathrm{D}$, et al. Anaerobic microbiology in 198 cases of pleural empyema: a Bulgarian study. Anaerobe. 2004;10:261-7.

26. Fournier PE, La MV, Casalta J, Richet H, Collart F, Raoult D. Finegoldia magna, an early post-operative cause of infectious endocarditis: report of two cases and review of the literature. Anaerobe. 2008;14:310-2.

27. Brook I. Anaerobic infections: diagnosis and management; New York: Informa Healthcare; 2008.

28. Mazmanian SK, Round JL, Kasper DL. A microbial symbiosis factor prevents intestinal inflammatory disease. Nature. 2008;29;453:620-5

29. Howden $\mathrm{CW}$, Hunt $\mathrm{RH}$. Relationship between gastric secretion and infection. Gut. 1987;28:96-107.

30. Segal R, Pogoleriuk I, Dan M, Baumoehl Y, Leibovitz A. Gastric microbiota in elderly patients fed via nasogastric tubes for prolonged periods. J Hosp Infect. 2006; 63:79-83.

31. Boris $S$, Barbés $C$. Role played by lactobacilli in controlling the population of vaginal pathogens. Microbes Infect. 2002;2:543-6.

32. Jousimies-Somer HR, Finegold SM. Problems encountered in clinical anaerobic bacteriology. Rev Infect Dis. 1984;6:45-50.

33. Hindiyeh M, Acevedo V, Carroll K. Comparison of three transport systems (Starplex StarSwab II, the new Copan Vi-Pak Amies Agar Gel collection and transport swabs, and BBL Port-A-Cul) for maintenance of anaerobic and fastidious aerobic organisms. J Clin Microbiol. 2001;39:377-80.

34. Dowell VR, Hawkins TM. Laboratory methods in anaerobic bacteriology - CDC laboratory manual. Atlanta: U.S. Department of Health, Education and Welfare, Center for Disease Control; 1974.

35. Holdeman LD, editor. Anaerobe Laboratory Manual. $4^{\text {th }}$ ed. Blacksburg: Virginia Polytechnic Institute and State University; 1977.

36. Nagy E, Urbán E, Sóki J, Terhes G, Nagy K. The place of molecular genetic methods in the diagnostics of human pathogenic anaerobic bacteria. A minireview. Acta Microbiol Immunol Hung. 2006;53:183-94.

37. Finegold SM. Perspective on susceptibility testing of anaerobic bacteria. Clin Infect Dis. 1997;25:S251-3. 